\title{
NAS SOMBRAS DA DITADURA: AS MARCAS DA VIOLÊNCIA EM UMA VARANDA SOBRE O SILÊNCIO E DE AMOR Y DE SOMBRA
}

\author{
Cristiane Aparecida da Rosa Rossi ${ }^{1}$
}

Resumo: Com base no estudo dos romances Uma varanda sobre o silêncio, do escritor brasileiro Josué Montello (1917-2006), e De amor y de sombra, da escritora chilena Isabel Allende (1942), pretendemos compreender a maneira como o autoritarismo político instaurado no Brasil, a partir de 1964 a 1985, conforma a vida do indivíduo, de modo a cercear sua liberdade, impedindo-o de agir livremente. Com base nisso, dizemos que o estado autoritário age como coator e intensificador do sofrimento humano, de modo a tornar o cidadão comum incapaz de governar sua vida, sem que a opressão condicione sua conduta. Dessa forma, a fim de realizarmos este estudo, faremos uma análise comparativa dos referidos romances, aliando-os à pesquisa bibliográfica. Os resultados apontarão para os desaparecimentos de Mário Júlio e de Evangelina Ranquileo como exemplos, casos de violência comumente encontrados no Brasil e no Chile, no período que sucedeu o golpe militar de 1964.

Palavras-chaves: Literatura. Ditadura militar. Autoritarismo. Repressão.

Abstract: From the study of the novels Uma varanda sobre o silêncio, written by the Brazilian author Josué Montello (1917-2006) and De amor y de sombra, by the Chilean writer Isabel Allende (1942), we aim to understand how the political authoritarianism introduced in Brazil, from 1964 to 1985, defines the lives of individuals, restricting their freedom and preventing them from acting freely. In this sense, we say that the authoritarian state acts as coercer and enhancer of the human suffering, in order to transform ordinary citizens unable to rule their lives, without the oppression afflicting and defining their behavior. Therefore, in order to accomplish this study, we will make a comparative analysis of these novels, besides bibliographic research. The results point to Mario Júlio and Evangelina Ranquileo are cases of violence commonly occurred in Brazil and Chile in the period that followed the military coup of 1964.

Keywords: Literature. Dictatorship military. Authoritarianism. Repression.

\section{INTRODUÇÃO}

A partir do golpe militar ocorrido em abril de 1964, teve início, no Brasil, um duro período repressivo denominado de ditadura militar. Durante esse período, que se estendeu de 1964 até o início dos anos de 1980, o território brasileiro e outros países do continente tornaram-se o cenário, onde episódios

\footnotetext{
${ }^{1}$ Mestranda em Estudos Literários do Programa de Pós-Graduação em Letras da UFSM. Orientadora Prof. ${ }^{\text {a }}$ Dr. ${ }^{\text {a }}$ Luciana Ferrari Montemezzo. E-maill: cristianerossi@yahoo.com.br
} 
de tortura, mortes e outros atentados formavam parte do cotidiano das pessoas.

Em meio aos acontecimentos do dia-a-dia, cidadãos comuns eram retirados de suas casas, muitas vezes com o propósito de serem torturados até que revelassem os nomes dos envolvidos em crimes contra o governo. Nesses casos, um grande número de pessoas consideradas subversivas desaparecia; alguns eram presos, outros exilados. Segundo as palavras do Arcebispo Metropolitano de São Paulo, Paulo Evaristo Arns:

\begin{abstract}
Não há ninguém na terra que consiga descrever a dor de quem viu um ente querido desaparecer atrás das grades da cadeia, sem mesmo poder adivinhar o que the aconteceu. O "desaparecido" transforma-se numa sombra que ao escurecer-se vai encobrindo a última luminosidade da existência terrena. (Arquidiocese de São Paulo, 1985, p. 12)
\end{abstract}

Tanto o romance de Isabel Allende quanto o de Josué Montello foram escritos nos anos oitenta do século passado, período no qual esteve em vigor a ditadura militar no Brasil e no Chile. Nesse período, ambos os países foram testemunhas de atentados políticos, como: terrorismo urbano, desaparecimentos, mortes, boicotes, entre outros acontecimentos capazes de ilustrar os horrores do período em que vigorou o autoritarismo e a repressão política no Cone Sul.

Dentre as características inerentes ao sistema repressivo, destacamos 0 excessivo controle do governo em relação aos acontecimentos e escândalos com potencial para despertar o alarme da população local. Neste sentido, ao analisarmos a obra De amor y de sombra, chamamos a atenção para a invasão da residência da família Ranquileo pela polícia política com o propósito de intimidar a jovem Evangelina Ranquileo. A adolescente, filha mais nova da referida família, costumava sofrer frequentes ataques convulsivos, sempre por volta do meio dia, chamando a atenção da comunidade local. A ocorrência do fenômeno causa imenso interesse na vizinhança que buscava descobrir alguma aplicação prática para os ataques:

Pronto los vecinos se enteraron de esas extravagancias y empezaron a fisgonear alrededor de la casa. Los más atrevidos merodeaban de temprano para ver el fenómeno de cerca y trataron de buscarle alguna aplicación práctica. Algunos sugirieron a Evangelina 
comunicarse con las ánimas del Purgatorio durante el ataque, adivinar el futuro o calmar la lluvia. Digna comprendió que si el asunto pasaba a dominio público, llegaría gente de todas partes a pisotear su huerto, ensuciar su patio y burlarse de su hija (Allende, 1998, p. $61)$.

Os referidos ataques convulsivos, conforme testemunha o excerto abaixo, punham a jovem em estado de transe, fato que foi, imediatamente, relacionado a efeitos paranormais, levando a jovem a obter a fama de santa. Este fato ocorreu após a realização de supostos pequenos prodígios pela jovem, como foi o caso da eliminação das verrugas da mão de um dos circunstantes, por exemplo:

\begin{abstract}
A las doce del mediodía Evangelina cayó sobre la cama. Su cuerpo se estremeció y un hondo, largo, terrible gemido la recorrió entera, como una llamada de amor. Comenzó a agitarse convulsivamente y se arqueó hacia atrás en un esfuerzo sobrehumano. En su rostro desfigurado se borró la expresión de niña simple que tenía poco antes y envejeció de súbito varios años. Una mueca de éxtasis, dolor o lujuria marcó sus facciones. La cama se remeció e Irene, aterrada, percibió que también la mesa a dos metros de distancia adquiría movimiento propio sin mediar fuerza alguna conocida. [...] Afuera los perros aullaban en un interminable lamento de catástrofe, coreando las voces de cánticos y rezos. Las jarras de latón bailaban en la alacena y extraños golpes azotaban el tejado como una granizada de guijarros. Un temblor continuo sacudia un entablado sobre las vigas del alero, donde la familia guardaba las provisiones, las semillas y las herramientas de labranza. De arriba cayó una lluvia de maíz escapado de los sacos, aumentando la sensación de pesadilla. Sobre la cama Evangelina Ranquileo se contorsionaba, víctima de impenetrables alucinaciones y urgencias misteriosas. El padre, oscuro, dedentado, con su patética expresión de payaso triste, observaba el abatido desde el umbral, sin acercarse. La madre permanecia al lado de la cama con los ojos entornados, intentando tal vez escuchar el silencio de Dios. Dentro y fuera de la casa la esperanza se apoderaba de los peregrinos. Uno a uno se aproximaron a Evangelina en demanda de su pequeño, humilde milagro (Allende, 1998, p. 71-72).
\end{abstract}

Transcrevemos, abaixo, o excerto descrevendo o dia da invasão da residência da jovem Evangelina Ranquileo pela polícia política:

Oyeron órdenes y antes que pudieran reaccionar, los militares invadieron en tropel, ocupando el patio y metiéndose a la casa con las armas en la mano. Apartaron a la gente a empujones, corrieron a los niños a gritos, golpearon con las culatas a quienes se pusieron por delante y llenaron el aire con sus voces de mando (Allende, 1998, p. 73). 
De Uma varanda sobre o silêncio, extraímos o diálogo abaixo, transcrevendo o momento em que o apartamento da protagonista é invadido pela polícia, em busca de informações capazes de relacionar o sumiço do filho da personagem ao sequestro e morte do filho do embaixador americano no Brasil.

\begin{abstract}
- Imagine o senhor que eu tivesse saído de casa, deixando as janelas escancaradas, e que, ali, na minha ausência, tivesse entrado um furacão. Pois foi essa a sensação que eu tive quando abri a porta do apartamento. Tudo revolvido, Tio Acrísio. Tudo. Até os quadros das paredes tinham sido revistados, para ver se ali havia algum cofre. No meu quarto, escancararam os gavetões da cômoda, abriram o guarda-roupa, até o cesto de roupa suja foi remexido [...]. Não pense o senhor que aquilo era obra de assaltante. Não, senhor. Apareceram uns homens da Polícia, todos armados. [...]. Eu queria que o senhor visse como ficou o quarto do Mário Júlio. Examinaram livro por livro, papel por papel. Bateram não sei quantas fotografias. Arrombaram as gavetas. Reviraram o colchão da cômoda, e ainda carregaram o caderno de telefone, as notas de estudo [...]. (Montello, 1984, p. 89)
\end{abstract}

Em ambos os trechos, podemos compreender o estado de insegurança que atemorizava a sociedade brasileira e chilena durante o período da repressão. Tanto no primeiro como no segundo excertos, as personagens das tramas têm suas residências invadidas pela polícia que, sem aviso nem autorização, adentram nos espaços, provocando aflição e angústia nos circunstantes.

Dessa forma, analisaremos a situação instaurada no Brasil, a partir de 1964 e, no Chile, a partir de 1973, durante o período em que vigorou o regime político ditatorial nesses países, nos romances de Josué Montello e Isabell Allende. O presente estudo propõe-se a refletir sobre as influências das perdas dos indivíduos na vida das pessoas. Como resultado, verificaremos que o destino dos cidadãos representa a ação de forças, cujo comando, por vezes, não depende do seu controle.

\title{
2. DE AMOR Y DE SOMBRA
}

A obra De amor y de sombra é o segundo romance de Isabel Allende, escrito em 1984. Em continuidade ao romance La casa de los espíritos (1982), 
De amor y de sombra contextualiza em sua narrativa o período correspondente à ditadura militar no Chile, em consequência ao golpe militar que retirou o governo do ex-presidente Salvador Allende do poder.

O romance De amor $y$ de sombra narra a história de Evangelina Ranquileo, a jovem de quinze anos que sofria ataques e convulsões inexplicáveis e que, por esse motivo, passou a ser considerada santa pelos habitantes locais. O caso chama a atenção da jornalista Irene que se dirige à localidade de Los Riscos para investigar o fato. Ao chegar ao local, Irene e o fotógrafo Francisco testemunham a invasão da residência por um grupo de militares da polícia e o rapto da jovem que é levada pelo grupo. A partir daí, a trama gira em torno da busca de Evangelina Ranquileo e a posterior descoberta de uma mina desativada que servia de cemitério clandestino às vítimas de diversos crimes políticos. Dessa forma, tanto Irene como Francisco, comprometem-se em descobrir e revelar os culpados pelos crimes, de modo que a jornalista acaba sofrendo em sua pele um atentado à bala que a obriga a abandonar o país.

\section{UMA VARANDA SOBRE O SILÊNCIO}

Josué Montello é quarto ocupante da cadeira no 29 da Academia Brasileira de Letras. O autor maranhense escreveu inúmeras obras, entre romances, crônicas e ensaio, dentre os quais podemos citar Os tambores de São Luís (1975), Noite sobre Alcântara (1978), A coroa de areia (1979), entre outros.

A obra Uma varanda sobre o silêncio narra a história de Luciana, uma frágil mulher obstinada pela volta do filho desaparecido, a quem dedicara toda sua vida, provendo-lhe de cuidados, sobretudo depois do fim de seu casamento.

Confiante e determinada, Luciana não perde a esperança de rever o filho Mário Júlio, o estudante de Engenharia, desaparecido, misteriosamente, depois de um fim de semana em que, como de costume, saíra com os amigos. O fato é imediatamente, relacionado a insurreições políticas, devido ao fato de que o 
desaparecimento do jovem se dá no mesmo dia em que ocorre o atentado contra o filho do embaixador americano no Brasil.

Durante o desenrolar da narrativa, Luciana procura notícias do filho, sem conseguir, no entanto, encontrar fatos novos capazes de fazê-lo retornar. De qualquer maneira, a angústia daquela mãe desperta comoção em algumas pessoas que prometem dar-lhe informações, muitas das quais resultam apenas em extorsão. Da mesma forma que em De amor y de sombra, o enredo de Uma varanda sobre o silêncio desenvolve-se durante o período em que a ditadura militar ocorreu em ambos os países.

\title{
4. O AUTORITARISMO POLÍTICO E A DITADURA MILITAR
}

Segundo o Dicionário de Política:

\begin{abstract}
Na tipologia dos sistemas políticos, são chamados de autoritários os regimes que privilegiam a autoridade governamental e diminuem de forma mais ou menos radical o consenso, concentrando o poder político nas mãos de uma só pessoa ou de um só órgão e colocando em posição secundária as instituições representativas (Stoppino, 2008, p. 94).
\end{abstract}

Com base nesta definição, entendemos que os sistemas autoritários são aqueles em que a autoridade se concentra nas mãos dos governantes, enquanto que às instituições representativas, cabe apenas uma parcela secundária do poder. Nesses casos, segundo o referido dicionário, a centralização da autoridade, característica inerente ao autoritarismo, "é condicionada por uma estrutura política profundamente hierárquica, por sua vez escorada numa visão de desigualdade entre os homens e exclui ou reduz ao mínimo a participação do povo no poder [...]" (Stoppino, 2008, p. 94). Dessa forma, durante a vigência dos regimes autoritários, é comum a utilização de meios coercitivos como forma de garantir o poder.

É importante salientar que o conceito de autoritarismo surge em contraposição ao conceito de democracia, o que significa dizer que, de maneira geral, o autoritarismo nega o princípio da igualdade entre os indivíduos.

O período de vigência da ditadura militar no Cone Sul foi repressivo, em que os indivíduos tinham sua liberdade cerceada pelo governo. $\mathrm{O}$ uso dos 
meios coercitivos obrigava-os a agirem em conformidade com os objetivos governamentais, quais sejam, manter a ordem e a população sob constante controle.

De acordo com Velho (apud Schwartz; Sosnowsli, 1994, p. 36): "Violência é o uso da força, da coerção, no sentido, no senso comum, para impor vontades, interesses, desejos, aspirações". Neste sentido, dizemos que a arbitrariedade do poder central deveu-se ao uso indiscriminado da força e da violência, como formas de assegurar o poder.

Ainda com relação à violência e ao autoritarismo, encontrados de maneira profusa durante a vigência da ditadura militar, salientamos que a centralização do poder nas mãos do exército impossibilitava o exercício da cidadania, visto que os cidadãos não tinham direito a escolher seus governantes e a participação política, no caso, era nula.

No episódio abaixo transcrito, encontramos elementos capazes de testemunhar as imposições da ditadura: repressão, prisões políticas, impressão clandestina de folhetos, entre outros:

El día del Golpe Militar creyó que se trataba de un grupo de sublevados a quienes las Fuerzas Armadas leales a la constitución y la república dominarían rápidamente. Varios años después seguía esperando lo mismo. Combatía a la dictadura con métodos estrafalarios. En pleno auge de la represión, cuando habilitaron hasta los estadios y las escuelas para encerrar millares de prisioneros políticos, el Profesor Leal imprimió unos volantes en su cocina, subió al último piso del edificio del Correo y los lanzó a la calle. Soplaba viento favorable y su misión fue exitosa, porque algunos ejemplares aterrizaron en el Ministerio de Defensa. (Allende, 1998, p. 192)

Abaixo, transcrevemos um trecho do romance Uma varanda sobre 0 silêncio, denunciando o clima de revolta juvenil e de insurreição política no qual se encontrava o Brasil naquele momento:

Somente os moços, no ambiente alarmado, reagiam à coerção da Polícia, pregando cartazes, distribuindo volantes, pichando muros e fachadas, organizando passeatas, sobretudo no âmbito das universidades, a despeito dos cavalarianos que por lá irrompiam, brandindo porretes, soltando bombas de gás lacrimogêneo. (Montello, 1984, p. 70) 
Conforme podemos constatar, em ambas as obras, encontramos evidências de um sistema autoritário e repressivo, em que, muitas vezes, os cidadãos eram obrigados a agir de maneira clandestina, a fim de não sofrerem as sanções do governo. Este, por sua vez, intentava conter o pânico da população, fazendo uso de forças coercitivas (porretes, bombas de gás lacrimogêneo) e repressivas, a fim de evitar o descontrole da situação.

\section{ANGÚSTIA E SUPERAÇÃO: AS FACES DA MESMA MOEDA}

A obra Uma varanda sobre o silêncio narra a história de Luciana, a mãe angustiada e zelosa, cujo sentido da vida passa a ser o de aguardar o retorno do filho, supostamente desaparecido, em decorrência do seu envolvimento com insurgências políticas. Em De amor y de sombra, a personagem principal é Irene, uma jornalista chilena, responsável pela investigação do caso da adolescente Evangelina Ranquileo. Conforme dissemos anteriormente, a jovem Evangelina foi retirada de casa pelos militares em consequência da repressão política, fato que permite à heroína Irene vivenciar, em sua pele, o tormento por que passavam muitas pessoas, na época da ditadura militar. Ou seja, em ambos os romances as personagens submetem-se a dramas e situações dolorosas capazes de alterar suas vidas. No romance de Josué Montello, Luciana expõe-se a situações perigosas, dirigindo-se sozinha, de madrugada, para um local afastado, com a finalidade de satisfazer as exigências de um extorsor. No romance de Isabel Allende, Irene quase perde a vida ao sofrer em sua pele um atentado à bala, o que a obriga a partir, em exílio, do país. Por esses motivos, ressaltamos que, em ambos os romances, a narrativa relacionase ao desaparecimento de uma pessoa, ou seja, Mário Júlio e Evangelina Ranquileo.

Neste sentido, dizemos que a angústia, produzida em ambientes de terror, gera predisposições interiores para que o indivíduo enfrente os dramas em busca de "atitudes construtivas que auxiliam a resolução das dificuldades". (ASSIS; et al, 2006, p. 07). Em outras palavras, o estado autoritário desempenha o papel de provocador e intensificador do sofrimento humano, de modo a tornar vida do cidadão comum impossibilitada de autogovernar-se. 


\title{
6. O BRASIL E A LITERATURA NOS ANOS DE CHUMBO
}

A literatura brasileira está repleta de inúmeros casos de narrativas relacionadas à violência. $O$ que ocorre é que a violência normalmente está associada aos conflitos sociais. De acordo com Guinzburg:

\begin{abstract}
A história brasileira é intensamente caracterizada pela presença de violência em processos sociais. (...) Uma percepção crítica de nosso passado histórico permite perceber que a violência não tem na vida brasileira apenas um lugar casual ou incidental. Ela tem uma função propriamente constitutiva: ela define condições de relacionamento público e privado, organiza instituições e estabelece papeis sociais. (In: Umbach; Calegari; Ourique, 2011, p. 147-148)
\end{abstract}

Durante o período que se sucedeu ao golpe militar de 1964, as manifestações literárias e artísticas permaneceram sob o crivo da censura: um dos mais temíveis aparatos do Estado. Ao longo desse período, a censura dos meios de comunicação impedia a população intelectual de expressar livremente seu pensamento, fazendo com que muitos trabalhos, textos, músicas, peças de teatro, entre outras manifestações artísticas e culturais, deixassem de serem publicadas ou recebessem adaptações pelos autores.

A partir do Ato Institucional no 5 (Al-5), baixado em 13 de dezembro de 1968, a política repressiva tornou-se acirrada, de modo a impedir os autores de divulgarem livremente sua produção artística e/ou literária. Isso significa que, durante a vigência do Ato Institucional $\mathrm{n}^{\circ}$ 5, os escritores censurados publicavam seus pensamentos sob a ditadura, de maneira camuflada, com uso de textos anônimos ou com pseudônimo ou por intermédio de uma linguagem figurada. A Lei da Anistia, promulgada no final dos anos 70, marca o começo de uma nova trajetória política no Brasil, possibilitando aos escritores e demais cidadãos banidos e exilados, o retorno à legalidade no país.

Dessa forma, compreendemos a importância de romances como Uma varanda sobre o silêncio por retratarem, ao longo de sua narrativa fictícia, a verossimilhança dos dramas vivenciados pela sociedade da época ditatorial, como os desaparecimentos, sequestros, mortes, entre outros aspectos que caracterizaram o terrorismo e o regime autoritário no Brasil. 


\section{CONSIDERAÇÕES FINAIS}

Ao relembrarmos os episódios narrados nos romances Uma varanda sobre o silêncio e De amor y de sombra, cujas narrativas transcorrem em cenários políticos autoritários, verificamos que a ditadura repercutiu, de maneira acentuada, sobre a produção literária do período; sobretudo após o início da censura dos meios de comunicação, ocorrido a partir de 1968.

Em ambos os romances em estudo, as personagens centrais das tramas têm suas vidas relacionadas a desaparecimentos de outras pessoas, em consequência das marcas da repressão. Conforme foi dito anteriormente, em De amor y de sombra, o início da trama ocorre com o rapto da adolescente Evangelina Ranquileo pelo militares. Em Uma varanda sobre o silêncio, a narrativa concentra-se em descobrir o paradeiro do estudante Mário Júlio, envolvido, possivelmente, em insurreições políticas. Desse modo os romances Uma varanda sobre o silêncio e De amor y de sombra nos emprestam suas histórias, em que podemos aliar realidade e ficção, com base nos acontecimentos narrados à época da ditadura militar, nesses países.

No Brasil, a vigência da ditadura militar manteve a população sob constante terror, ou seja, durante esse período, a censura impossibilitava a publicação de diversas manifestações intelectuais. Dessa forma, inúmeros escritores, músicos e outros artistas da época procuravam expressar, em sua arte, as angústias do momento, de maneira disfarçada, sem que pensamentos de revolta alarmassem e atemorizassem a população.

Tendo em vista os fatos mencionados: censura, repressão, coação, dizemos que o estado autoritário age como provocador e intensificador do sofrimento humano, devido à sua ação repressora, capaz de obrigar o indivíduo a agir em conformidade com as determinações governamentais. $O$ que podemos concluir é que um dos objetivos do governo militar consistia em manter a população sob controle, valendo-se de ameaças e de violência, a fim de não perder o poder. 


\section{REFERÊNCIAS}

ACADEMIA BRASILEIRA DE LETRAS. Disponível em: $<$ http://www.academia.org.br/abl/cgi/cgilua.exe/sys/start.htm?infoid=788\&sid=2 84>. Acesso em: 30 nov. 2014.

ALLENDE, Isabel. De amor y de sombra. Barcelona: Plaza \& Janés Editores, 1998.

ARQUIDIOCESE DE SÃO PAULO. Brasil: nunca mais. Petrópolis: Vozes, 1985.

ASSIS, S. G. et al. Superação de dificuldades na infância e adolescência: conversando com profissionais de saúde sobre resiliência e promoção da saúde. Rio de janeiro: FIOCRUZ/ENSP/CLAVES/CNPq, 2006.

GUINZBURG, Jaime. A violência na literatura brasileira. In: UMBACH, Rosani. K.; CALEGARI, Lizandro. C. (Org). Estética e política na produção cultural: as memórias da repressão. Santa Maria: Ed. da UFSM, 2011.

MONTELLO, Josué. Uma varanda sobre o silêncio. Rio de Janeiro: Nova Fronteira, 1984.

NAVARRO, Márcia Hoppe. O romance na América Latina. Porto Alegre: Ed. da UFRGS; MEC/SESU/PROEDI, 1998.

PADRÓS, E. S.; BARBOSA, V. M.; LOPEZ, V. A.; FERNANDES, A. S. (Org.). A ditadura de segurança nacional no Rio Grande do Sul (1964-1985): história e memória. Porto Alegre: Corga, 2010.

STOPPINO, M. Autoritarismo. In: BOBBIO, N.; MATTENCCI, N; PASQUINO, G. Dicionário de Política. 13. ed. Brasília: Ed. da UNB, 2008. Vol. 1.

UMBACH, R. K.; CALEGARI, L. C. OURIQUE, J. L. P. Violência e memória na produção cultural: o autoritarismo na Alemanha e no Brasil. Santa Maria: Ed. do PPGL, 2012.

VELHO, G. Autoritarismo e violência no Brasil contemporâneo. In: SCHWARTZ, J.; SOSNOWSKI, S. (Org.). Brasil: o trânsito da memória. São Paulo: Edusjo, 1994. 